\title{
Putative Channel Components for the Fast-Rotating Sodium- Driven Flagellar Motor of a Marine Bacterium
}

\author{
YUKAKO ASAI, SEIJI KOJIMA, HARUKI KATO, NORIKO NISHIOKA, IKURO KAWAGISHI, \\ AND MICHIO HOMMA* \\ Division of Biological Science, Graduate School of Science, Nagoya University, Chikusa-Ku, Nagoya 464-01, Japan
}

Received 8 April 1997/Accepted 13 June 1997

\begin{abstract}
The polar flagellum of Vibrio alginolyticus rotates remarkably fast (up to 1,700 revolutions per second) by using a motor driven by sodium ions. Two genes, $\operatorname{mot} X$ and $\operatorname{mot} Y$, for the sodium-driven flagellar motor have been identified in marine bacteria, Vibrio parahaemolyticus and $V$. alginolyticus. They have no similarity to the genes for proton-driven motors, $\operatorname{mot} A$ and $\operatorname{mot} B$, whose products constitute a proton channel. MotX was proposed to be a component of a sodium channel. Here we identified additional sodium motor genes, $p o m A$ and pomB, in $V$. alginolyticus. Unexpectedly, PomA and PomB have similarities to MotA and MotB, respectively, especially in the predicted transmembrane regions. These results suggest that PomA and PomB may be sodium-conducting channel components of the sodium-driven motor and that the motor part consists of the products of at least four genes, $\operatorname{pom} A, \operatorname{pomB}, \operatorname{mot} X$, and $\operatorname{mot} Y$. Furthermore, swimming speed was controlled by the expression level of the pom $A$ gene, suggesting that newly synthesized PomA proteins, which are components of a force-generating unit, were successively integrated into the defective motor complexes. These findings imply that $\mathrm{Na}^{+}$-driven flagellar motors may have similar structure and function as proton-driven motors, but with some interesting differences as well, and it is possible to compare and study the coupling mechanisms of the sodium and proton ion flux for the force generation.
\end{abstract}

The bacterial flagellar motor rotates the helical flagellar filament that extends from the cell body to propel the cell. The energy source for motor rotation is the electrochemical gradient of a specific ion (either a proton or a sodium ion) across the cytoplasmic membrane (6). Thus, the flagellar motor is a molecular machine that couples ion flux to force generation. The proton-driven motors of bacterial flagella have been extensively studied in terms of structure, genetics, biochemistry, and biophysics. Five proteins, MotA, MotB, FliG, FliM, and FliN, appear to be involved in force generation of proton-driven motors. It has been proposed that FliG, FliM, and FliN make a switch complex and function as the rotor of the flagellar motor $(27,51)$. They form the $\mathrm{C}$ ring, which was newly found on the cytoplasmic face of the MS ring $(13,53)$. MotA and MotB, which are the membrane proteins and have four transmembrane segments and one transmembrane segment, respectively, are associated in a complex and function as a protonconducting channel $(6,8,47)$. MotB is believed to act as an anchor to the cell wall $(11,12)$ and to work with MotA as the stator of the flagellar motor. It has been shown that MotA interacts, but only weakly, with FliG and FliM of the switch complex (49).

Sodium-driven motors have advantages for experimental analysis, since sodium motive force can be manipulated more readily than proton motive force $(18,19,52)$. Moreover, amiloride and its analogs, which specifically and strongly inhibit the polar-flagellum motors, are available and are thought to interact with a sodium channel of the flagellar motor $(1,3,48)$. Some marine Vibrio species have two types of flagella, polar (Pof) and lateral (Laf), which are rotated by sodium- and proton-driven motors, respectively, in the same cell $(2,21)$. The polar flagella work better for swimming in a liquid or a low-viscosity environment (4). By laser dark-field microscopy,

* Corresponding author. Phone: 52-789-2992. Fax: 52-789-3001. Email: g44416a@nucc.cc.nagoya-u.ac.jp. it has been shown that the rotation of the polar flagella is very fast in Vibrio alginolyticus; speeds of ca. 600 revolutions per s (rps) are observed in $50 \mathrm{mM} \mathrm{NaCl}$ at room temperature, and surprisingly, the speeds increase up to ca. 1,700 rps in $300 \mathrm{mM}$ $\mathrm{NaCl}$ at $35^{\circ} \mathrm{C}(28,29,37)$.

The rotation of the sodium-driven motor seems to be very stable at high speed (37). When the rotation rate is reduced by amiloride, the motor still rotates smoothly though the rotation rate tends to fluctuate. On the other hand, polar flagella showed remarkably larger speed fluctuations upon addition of phenamil, an amiloride analog (38). The speed fluctuations induced by phenamil were explained by a low rate of dissociation of the inhibitor from the force-generating unit. Mutants resistant to phenamil were isolated, and the $K_{i}$ value for phenamil in the resistant strain was estimated to be five times larger than that in the wild-type strain. By analysis of motor speed fluctuations, it was suggested that a phenamil-specific binding site of the motor was mutated in the resistant strain (24). The resistance mutation may map to one of the genes coding for the motor proteins.

Recently, the mot $X$ and $\operatorname{mot} Y$ genes, which seem to encode components of the force-generating units of the $\mathrm{Na}^{+}$motor, were isolated from Vibrio parahaemolyticus $(30,31)$. However, the predicted products have no homology to MotA and MotB, which are components of the force-generating units of $\mathrm{H}^{+}$ motors and are thought to form a $\mathrm{H}^{+}$channel $(6,8,44)$. On the other hand, the C-terminal domains of MotY and MotB do have sequence similarities to peptidoglycan-interacting proteins. MotX is inferred to be a component of the $\mathrm{Na}^{+}$channel of the motor because overproduction of MotX was lethal to Escherichia coli in proportion to the external $\mathrm{Na}^{+}$concentration, and this effect was suppressed by the addition of amiloride (31). Genes identical to the $\operatorname{mot} X$ and $\operatorname{mot} Y \mathrm{Na}^{+}$motor genes were also detected in $V$. alginolyticus (reference 40 and unpublished data). So, it had been thought that the forcegenerating units of $\mathrm{H}^{+}$and $\mathrm{Na}^{+}$motors were very different. MotX and MotY of the $\mathrm{Na}^{+}$motor, each of which has a 
TABLE 1. Bacterial strains and plasmids

\begin{tabular}{|c|c|c|}
\hline Strain or plasmid & Genotype or description ${ }^{a}$ & $\begin{array}{l}\text { Reference } \\
\text { or source }\end{array}$ \\
\hline \multicolumn{3}{|l|}{ V. alginolyticus strains } \\
\hline $138-2$ & Wild type & 50 \\
\hline VIK4 & 138-2 rif $\left(\mathrm{Rif}^{\mathrm{r}} \mathrm{Pof}^{+} \mathrm{Laf}^{+}\right)$ & 40 \\
\hline VIO5 & VIK4 laf $\left(\mathrm{Pof}^{+} \mathrm{Laf}^{-}\right)$ & 40 \\
\hline VIO586 & VIO5 pomA $\left(\mathrm{Laf}^{-} \mathrm{Pom}^{-}\right)$ & This work \\
\hline \multicolumn{3}{|l|}{ V. parahaemolyticus } \\
\hline LM4170 & lafX313 motX118 $\left(\mathrm{Laf}^{-} \mathrm{Pom}^{-}\right)$ & 31 \\
\hline LM4171 & lafX313 motY141 $\left(\mathrm{Laf}^{-} \mathrm{Pom}^{-}\right)$ & 30 \\
\hline \multicolumn{3}{|l|}{ E. coli strains } \\
\hline DH5 $\alpha$ & $\mathrm{F}^{-} \lambda^{-}$recA1 hsdR17 endA1 supE44 thi-1 relA1 gyrA96 $\Delta$ (argF-lacZYA)U169 $\phi 80 \mathrm{~d} l a c Z \Delta \mathrm{M} 15$ & 16 \\
\hline XL1-Blue & recA1 hsdR17 endA1 supE44 $\Delta($ lac-proAB $)\left\{\mathrm{F}^{\prime}:: \operatorname{Tn} 10\right.$ proAB lacI $\left.{ }^{\mathrm{q}} Z \Delta \mathrm{M} 15\right\}$ & Stratagene \\
\hline S17-1 & rec $A$ hsdR thi pro ara $\mathrm{RP}-4$ 2-Tc::Mu-Km::Tn7 $\left(\mathrm{Tp}^{\mathrm{r}} \mathrm{Sm}^{\mathrm{r}}\right)$ & 46 \\
\hline \multicolumn{3}{|l|}{ Plasmids } \\
\hline pSU21 & cat $\left(\mathrm{Cm}^{\mathrm{r}}\right) \mathrm{P}_{\text {lac }}$ lac $Z \alpha$ & 5 \\
\hline pSU41 & kan $\left(\mathrm{Km}^{\mathrm{r}}\right) \mathrm{P}_{\text {lac }}$ lac $\mathrm{Z} \alpha$ (MCS same as that in $\left.\mathrm{pSU} 21\right)$ & 5 \\
\hline pIO3 & pSU21 0.4-kb and 6.0-kb HindIII fragment $\left(\operatorname{mot} Y^{+}\right)$ & 40 \\
\hline pYA101 & pSU21 5.0-kb and 3.6-kb HindIII fragment (pomA) & This work \\
\hline pYA201 & pSU21 5.2-kb and 3.3-kb EcoRI fragment $\left(\right.$ pom $\left.A^{+}\right)$ & This work \\
\hline pYA202 & pSU21 3.3-kb EcoRI fragment $\left(\right.$ pom $\left.A^{+}\right)$ & This work \\
\hline pYA2021 & pSU21 2.7-kb EcoRI-HindIII fragment (pomA) & This work \\
\hline pYA2022 & pSU21 1.9-kb EcoRI-XbaI fragment (pom $A$ ) & This work \\
\hline pYA2023 & pSU21 1.6-kb EcoRI-SacI fragment (pomA) & This work \\
\hline pYA203 & $\begin{array}{l}\text { pSU21 3.3-kb EcoRI fragment (pom } A^{+} \text {) (containing the same fragment as pYA202, but in } \\
\text { the opposite orientation) }\end{array}$ & This work \\
\hline pYA2031 & pSU21 2-kb SacI-EcoRI fragment $\left(\right.$ pom $\left.^{+}\right)$ & This work \\
\hline pYA2032 & pSU21 $1.45-\mathrm{kb} X b a \mathrm{I}-E c o$ RI fragment $\left(\right.$ pom $\left.^{+}\right)$ & This study \\
\hline pHK2 & pSU21 3.3-kb SacI fragment $\left(\right.$ pom $\left.A B^{+}\right)$ & This work \\
\hline pHK3 & pSU21 1.2-kb HindIII-SacI fragment pomA pomB ${ }^{+}$) & This work \\
\hline pSK1 & pSU41 1.45-kb XbaI-EcoRI fragment $\left(\right.$ pom $\left.A^{+}\right)$ & This work \\
\hline pSK1- $\Delta 28$ & pSU41 with 329 bp deleted from $X b a$ I site of pSK1; lack of the native promoter & This work \\
\hline pMMB206 & cat $\left(\mathrm{Cm}^{\mathrm{r}}\right)$ IncQ lacI ${ }^{\mathrm{q}} \Delta$ bla $\mathrm{P}_{\text {tac-lac }}$ lac $\mathrm{Z} \alpha \mathrm{rrnB}$ & 35 \\
\hline
\end{tabular}

${ }^{a} \mathrm{Cm}^{\mathrm{r}}$, chloramphenicol resistant; $\mathrm{Km}^{\mathrm{r}}$, kanamycin resistant; $\mathrm{MCS}$, multicloning site; $\mathrm{P}_{\text {lac }}$, lac promoter; $\mathrm{P}_{\text {tac-lac }}$, tandemly located tac and lac promoters; Rif ${ }^{\mathrm{r}}$, rifampin resistant; $\mathrm{Sm}^{\mathrm{r}}$, streptomycin resistant; $\mathrm{Tp}^{\mathrm{r}}$, trimethoprim resistant.

putative single transmembrane region, were thought to form a channel component and/or a stator component, functionally homologous to the $\mathrm{H}^{+}$motor components MotA and MotB. However, in this study, we isolated novel pom (polar flagellum motility) genes whose predicted products are structurally homologous to the $\mathrm{H}^{+}$motor components, MotA and MotB. This shows that the channel components of the $\mathrm{Na}^{+}$motor are similar to those of the $\mathrm{H}^{+}$motor.

\section{MATERIALS AND METHODS}

Bacterial strains, plasmids, and growth conditions. The strains and plasmids used are shown in Table 1. V. alginolyticus and $V$. parahaemolyticus cells were cultured at $30^{\circ} \mathrm{C}$ in $\mathrm{VC}$ medium $(0.5 \%$ polypeptone, $0.5 \%$ yeast extract, $0.4 \%$ $\mathrm{K}_{2} \mathrm{HPO}_{4}, 3 \% \mathrm{NaCl}, 0.2 \%$ glucose) or VPG medium ( $1 \%$ polypeptone, $0.4 \%$ $\mathrm{K}_{2} \mathrm{HPO}_{4}, 3 \% \mathrm{NaCl}, 0.5 \%$ glycerol). When necessary, chloramphenicol and kanamycin were added at the final concentrations of 2.5 and $100 \mu \mathrm{g} / \mathrm{ml}$, respectively.

DNA manipulations and sequencing. Routine DNA manipulations were carried out according to the standard procedures (41). Restriction endonucleases and other enzymes for DNA manipulations were purchased from Takara Shuzo (Kyoto, Japan) and New England Biolabs (Beverly, Mass.). The nucleotide sequence was determined by the dideoxy chain termination method using the Sequenase version 2.0 DNA sequencing kit (United States Biochemical Corp. Cleveland, Ohio). $\left[\alpha-{ }^{32} \mathrm{P}\right] \mathrm{dCTP}(3,000 \mu \mathrm{Ci} / \mathrm{mmol}$; Amersham Japan, Tokyo, Japan) was used for radioactive labeling.

Electroporation. Transformation of Vibrio cells by electroporation was carried out as described previously (22). The cells were subjected to osmotic shock and were washed thoroughly with $20 \mathrm{mM} \mathrm{MgSO}_{4}$. Electroporation was carried out with the Gene Pulser electroporation apparatus (Japan Bio-Rad Laboratories, Tokyo, Japan) at an electric field strength between 5.0 and $7.5 \mathrm{kV} / \mathrm{cm}$.

Isolation of pom mutants. From the lateral flagellum-defective $\left(\mathrm{Pof}^{+} \mathrm{Laf}^{-}\right)$ mutants VIO5 (40), YM4 (17), and NMB201 or NMB205 (24), swarm-deficient mutants were isolated and pom mutants were selected from the swarm-deficient mutants as described previously (40).

pom gene cloning. Plasmid pSU21 (5) and chromosomal DNA from $V$. alginolyticus VIO5 were digested with EcoRI or HindIII and ligated. These DNA libraries were transferred into pom mutant (VIO586) cells by electroporation and selected as described previously (40). Cells were incubated at $30^{\circ} \mathrm{C}$ on $0.3 \%$ agar-VPG plates containing chloramphenicol.

Conjugation. Plasmid transfer by conjugation was carried out according to the method of Okunishi et al. (40). Aliquots ( $20 \mu \mathrm{l}$ each) of fresh overnight cultures of E. coli S17-1 cells carrying plasmid pMMB206 (donor) and Vibrio cells were mixed on a $1.25 \%$ agar-VC plate and incubated at $30^{\circ} \mathrm{C}$ overnight. Cells were scraped from the plate and suspended in $100 \mu \mathrm{l}$ of VC medium. To select transconjugants, the suspension was plated on a $1.25 \%$ agar-VC plate supplemented with $2.5 \mu \mathrm{g}$ of chloramphenicol per $\mathrm{ml}$.

Measurement of swimming speed. Cell culture was diluted about 100 -fold into Tris motility buffer ( $50 \mathrm{mM}$ Tris- $\mathrm{HCl}$ [pH 7.5], $5 \mathrm{mM} \mathrm{MgCl}_{2}, 5 \mathrm{mM}$ glucose, 50 $\mathrm{mM} \mathrm{NaCl}, 250 \mathrm{mM} \mathrm{KCl}$ ), and motility of the cells was observed under a darkfield microscope and recorded on videotape. Swimming speed was determined as described previously (17).

Nucleotide sequence accession number. The nucleotide sequences for the pom $A$ and pomB genes from $V$. alginolyticus have been deposited in DDBJ under accession no. AB004068.

\section{RESULTS}

Cloning of a pom gene required for polar flagellar rotation. We isolated pom (polar flagellar motility) mutants which have paralyzed polar flagella (40). Using a pom mutant (VIO586) as a recipient for shotgun cloning, we cloned a pom gene in pYA101 and pYA201 by using HindIII and EcoRI, respectively. When these plasmids were introduced into VIO586 cells, the cells swarmed in the $0.3 \%$ agar-VPG plate (Fig. 1A 
(A)

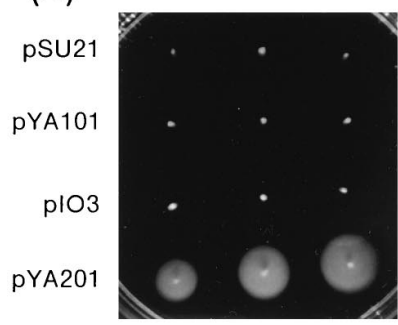

(B)

plO3

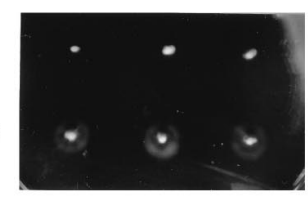

(C)

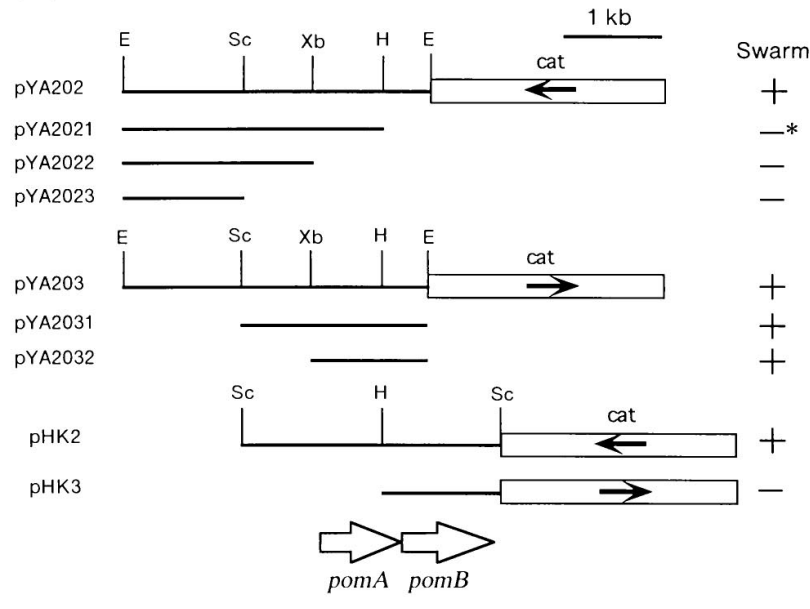

FIG. 1. Isolation of novel pom genes. (A and B) Swarming abilities of VIO586 cells carrying various plasmids. Fresh colonies were inoculated in $0.3 \%$ agar-VPG plates containing chloramphenicol and incubated at $30^{\circ} \mathrm{C}$ for 5 (A) and 9 (B) h. (C) Restriction map of plasmids. The swarm recovery of VIO586 by transformation of the plasmids in $0.3 \%$ agar-VPG plates is shown on the right side of the map. The chromosomal DNA fragments are indicated by solid lines. CAT indicates the chloramphenicol acetyltransferase gene from the vector pSU21 (5). The open arrows show the coding regions of PomA and PomB. A plasmid (pYA2021) containing a 2.7-kb HindIII-EcoRI fragment made small swarms after a long incubation (-*). Probably the functional pom gene was formed by homologous recombination between the mutant pom gene on the chromosome and a part of the pom gene on the plasmid. Restriction sites are shown as follows: E, EcoRI; H, HindIII; Sc, SacI; Xb, XbaI.

and 1B). Cells with pYA201 could swarm in $5 \mathrm{~h}$; however, cells with pYA101 could make only small swarms in $9 \mathrm{~h}$. pYA101 seemed not to contain the complete gene. Therefore, we used pYA201 for further analysis. The fragment in pYA201 did not complement mot $X$ and mot $Y$ mutants of $V$. parahaemolyticus or a mot $Y$ mutant of $V$. alginolyticus (data not shown), and the plasmid pIO3 carrying the mot $Y$ gene of $V$. alginolyticus (40) did not complement the pom mutant. So, this gene must be a novel one related to the sodium-driven motor. A 3.2-kb EcoRI fragment, which still complemented the pom mutant, was subcloned, and the resulting plasmid was named pYA202. Next, we made restriction maps of pYA202 and pYA203 (which has the same fragment as pYA202 but in the opposite orientation) and constructed various deletion derivatives. Complementation assays using deletion derivative plasmids revealed that the pom gene was located in the $1.45-\mathrm{kb} X b a \mathrm{I}-E c o$ RI fragment containing the HindIII site (Fig. 1C). The plasmid containing the fragment is pYA2032. After sequencing the fragment (see below), we found that it also contained part of a second pom gene. To clone the whole gene, shotgun cloning and screening were done with $S a c I$, which cut out a ca. 3.0-kb chromosomal
(A)

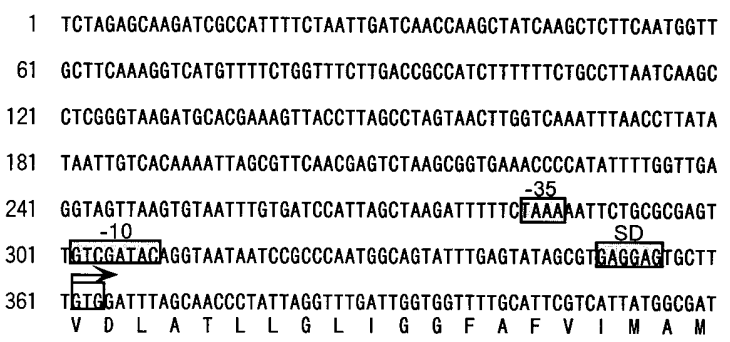

(B)

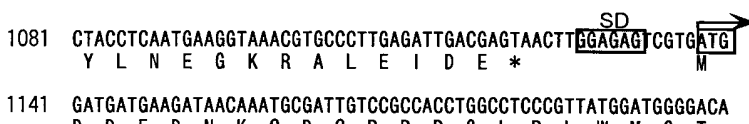

(C)

2041 CAAGGCGAGCCTCTCTACAGCGAAGAAGTGCCGGTAATTCAATAACTAGGCTTTAGTTTT

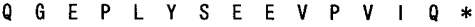

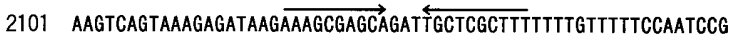

2161 CTtGgGtgtataATCTTGCGCCTTAAAAGTGAGCTC

FIG. 2. The promoter region of pom $A$ (A), the noncoding region between pom $A$ and $\operatorname{pom} B(\mathrm{~B})$, and the terminator region of pomB (C) in the 2,196-bp $X b a \mathrm{I}-S a c \mathrm{I}$ fragment. The sequences enclosed by boxes indicate the predicted promoter region, Shine-Dalgarno (SD) sequences, and start codons. The complementary sequences are shown by arrows.

fragment which hybridized to the $1.45-\mathrm{kb} X b a \mathrm{I}-E c o$ RI fragment (data not shown). Plasmid pHK2, containing the ca. 3.0-kb SacI fragment, complemented the mutation of VIO586.

Nucleotide sequence of the pom genes. We determined the nucleotide sequence of the 2,196-bp $\mathrm{XbaI}$-SacI fragment and identified two open reading frames, which we named pom $A$ and pomB; they encode proteins containing 253 and 315 amino acids, respectively. A consensus of ribosome binding sites was found at 12 and $11 \mathrm{bp}$ upstream from the start codons of pom $A$ and pomB, respectively (Fig. $2 \mathrm{~A}$ and $\mathrm{B}$ ). There are only $15 \mathrm{bp}$ between the two genes (Fig. 2B). Thirty-five base pairs downstream of the stop codon of $\operatorname{pom} B$, there is a consensus $\rho$ independent transcription termination site (Fig. 2C). A potential promoter sequence of TAAA $\left(\mathrm{N}_{15}\right)$ GTCGATAC, which is very similar to the $\sigma^{28}$ promoter consensus of TAAA $\left(\mathrm{N}_{15}\right) \mathrm{GC}$ CGATAA of Salmonella typhimurium and E. coli $(32,40)$, was found $67 \mathrm{bp}$ upstream of the start codon (Fig. 2A). Thus, the two genes seem to constitute a single transcription unit. A plasmid, pHK3 (Fig. 1C), containing only the pomB gene complemented the pom strains NMB104, NMB152, and NMB161. This indicates that the three strains are pomB mutants and that PomB is actually required for polar flagellar motility.

Comparison of PomA and PomB to MotA and MotB of $\mathbf{H}^{+}$ motor. The PomA and PomB proteins were found to be homologous to the proton-driven motor proteins, MotA and MotB, respectively, of Rhodobacter sphaeroides, Bacillus subtilis, and E. coli (Fig. 3). The hydropathy profiles of PomA and PomB are very similar to those of MotA and MotB of E. coli (data not shown), which have been shown to have four and one membrane-spanning helices, respectively. As with $m o t A$ and $m o t B$ in $E$. coli or B. subtilis, pom $A$ and pomB are in the same operon and have a $\sigma^{28}$-type promoter sequence upstream. In $E$. coli, che $A$ and che $W$ reside downstream of the mot genes in the same operon. In $V$. alginolyticus, as in $R$. sphaeroides, the operon contains only the two motor genes. Upstream of pomA, we found genes homologous to $E$. coli $x s e B$ and isp $A$, which 
(A)

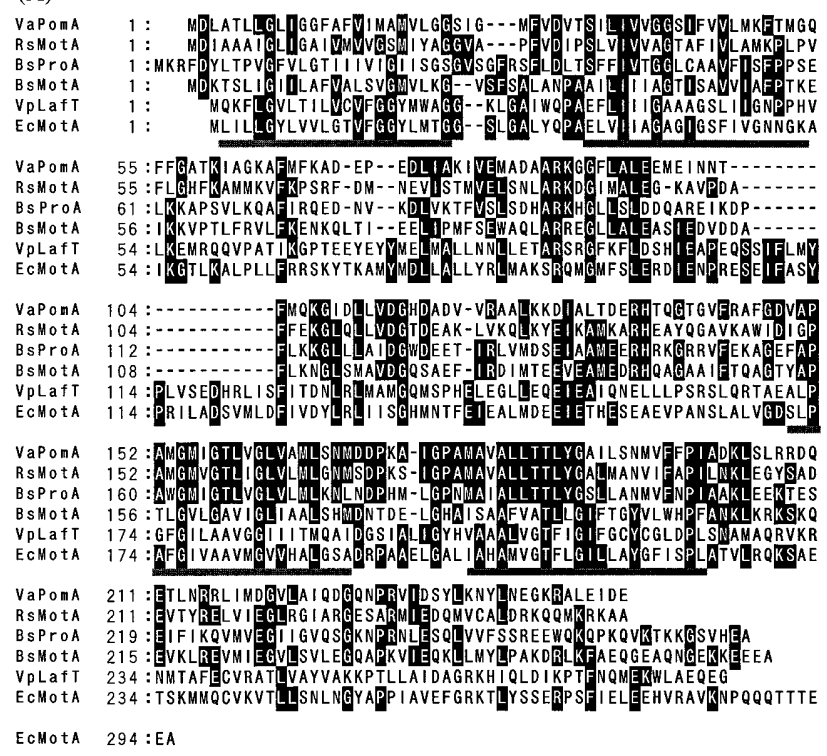

(B)

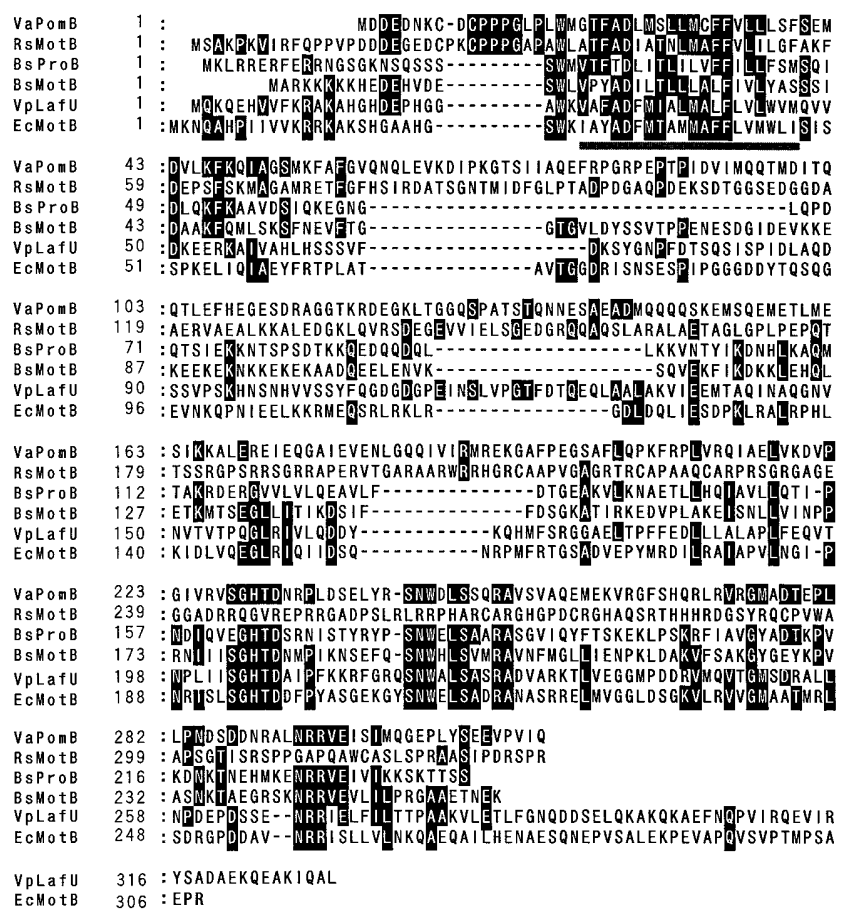

FIG. 3. Amino acid alignments of PomA (A) and PomB (B) with homologous proteins of various species. Dotted bars indicate membrane-spanning regions of $E$. coli MotA and MotB. Abbreviations: VaPomA, V. alginolyticus PomA; RsMotA, R. sphaeroides MotA; BsProA, B. subtilis hypothetical protein A; BsMotA, B. subtilis MotA; VpLafT, V. parahaemolyticus LafT; EcMotA, E. coli MotA; VaPomB, V. alginolyticus PomB; RsMotB, R. sphaeroides MotB; BsProB, B. subtilis hypothetical protein B; BsMotB, B. subtilis MotB; VpLafU, V. parahaemolyticus LafU; EcMotB, E. coli MotB. White letters in black boxes show identical residues.

encode the exoDNase small subunit and the farnesyl diphosphate synthase (14), respectively. The other sodium motor genes, mot $X$ and mot $Y$, are localized elsewhere on the chromosome $(30,31,40)$.

Figure $3 \mathrm{~A}$ shows the alignments of PomA with various MotA sequences. The four membrane-spanning regions, especially the third and fourth, are more similar than the other regions and, in MotA, are thought to form the proton channel. It has been shown that nonmotile or severe mot mutations are localized in the four membrane-spanning regions of MotA of E. coli (9). PomA is more similar to MotA of $B$. subtilis than to MotA of $E$. coli, even though the latter is phylogenetically closer to $V$. alginolyticus. PomA and $R$. sphaeroides MotA (43) are extremely similar and contain the same number of residues. It would be interesting to see whether these motor components are functionally interchangeable. For example, the channel components of proton-type and sodium-type $F_{0} F_{1}$ ATPases are similar, and it has been shown that the substitution of only two amino acids changes the ion specificity of $\mathrm{F}_{0} \mathrm{~F}_{1}$ ATPase (20).

PomB consists of 315 amino acids, and the N-terminal and the C-terminal regions are similar to those of MotB in other species (Fig. 3B). In those C-terminal regions of $V$. alginolyticus and $E$. coli, the peptidoglycan-binding motif is highly conserved but $R$. sphaeroides does not have the motif (42). The membrane-spanning region at the $\mathrm{N}$ terminus of MotB is thought to complex with the transmembrane regions of MotA and form a part of the proton channel (45). The N-terminal regions of PomB and $R$. sphaeroides MotB (42) are very similar. These results suggest that PomB also has only one membrane-spanning region and interacts with the cell wall peptidoglycan via its C-terminal domain.
Controlled expression of pom $A$ in $V$. alginolyticus. The $X b a \mathrm{I}-$ EcoRI fragment of pYA2032 was subcloned into the pSU41 vector (5). From the resultant plasmid, pSK1, various lengths of deletion were carried out with exonuclease III and mung

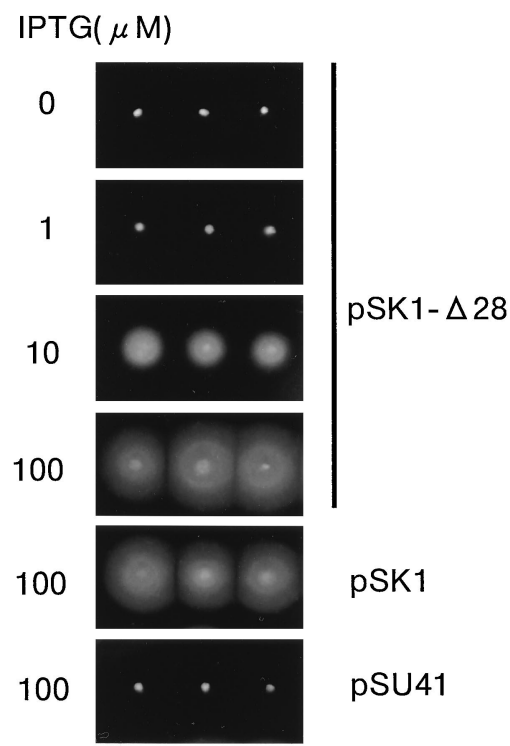

FIG. 4. Swarming profile by controlled expression of pomA. After pSK1- $\Delta 28$, pSK1, and pSU41 were introduced into VIO586/pMMB206, fresh overnight colonies were spotted on $0.25 \%$ agar-VC plates containing $2.5 \mu \mathrm{g}$ of chloramphenicol per ml, $100 \mu \mathrm{g}$ of kanamycin per $\mathrm{ml}$, and various concentrations of IPTG. The plates were incubated for $5 \mathrm{~h}$ at $30^{\circ} \mathrm{C}$. 
(A)

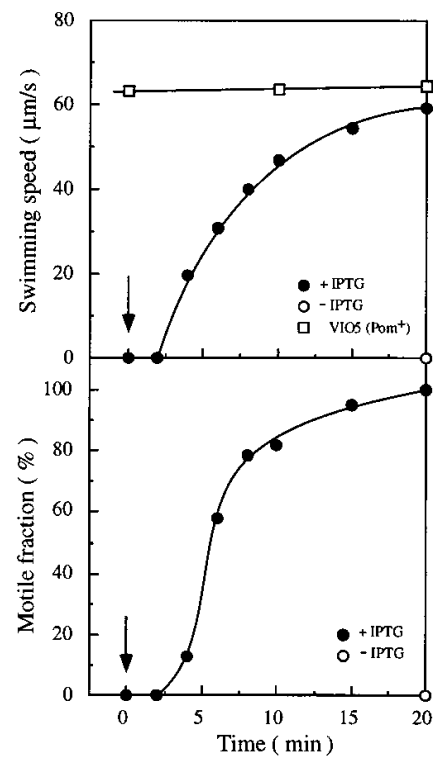

(B)

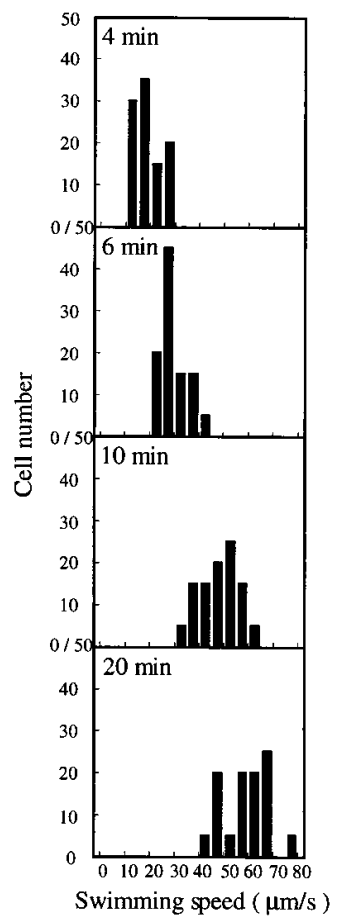

FIG. 5. Motility recovery by controlled expression of pomA. (A) For motility assay, VIO586/pMMB206/pSK1- $\Delta 28$ was grown in VPG medium containing 50 $\mathrm{mM} \mathrm{NaCl}$ and $250 \mathrm{mM} \mathrm{KCl}$ at $30^{\circ} \mathrm{C}$. At late logarithmic phase, $100 \mu \mathrm{M}$ IPTG was added to the medium (indicated by arrows). At various times, swimming speeds of motile cells were measured. The average swimming speed was obtained by measuring at least 20 cells. The motile fraction was determined by counting the number of motile cells among the total cells in one video image and averaging at least three images in one condition. (B) The distributions of swimming speeds in panel $\mathrm{A}$ at $4,6,10$, and $20 \mathrm{~min}$ are shown as the fractions of the total counted cells.

bean nuclease, and pom $A$ was placed under the control of a lac promoter-repressor system that had been established previously in $V$. alginolyticus (40) (Fig. 4). The putative $\sigma^{28}$ promoter sequence was deleted in plasmids pSK1- $\Delta 28$ and pSK1$\Delta 32$ (with deletion endpoints at 329 and $346 \mathrm{bp}$, respectively, in Fig. 2A). The motility of VIO586/pMMB206 cells carrying either of the plasmids was clearly dependent on the concentration of IPTG (isopropyl- $\beta$-D-thiogalactopyranoside). Figure $5 \mathrm{~A}$ shows the restoration of the swimming speed and motile fraction of VIO586/pMMB206/pSK1- $\Delta 28$ cells after the induction of pomA expression by IPTG. At $4 \mathrm{~min}$, cells began to swim slowly, and the swimming speed gradually increased, reaching wild-type level at $20 \mathrm{~min}$. The motile fraction showed almost the same profile as the swimming speed. After induction, the peak of the distribution progressively shifted from low swimming speed to high (Fig. 5B). The number of polar flagella is usually only one in a Vibrio cell, and the swimming speed of the cell reflects the motor property. These results suggest that newly synthesized PomA proteins were successively integrated into the defective motor complexes as shown in the $\mathrm{H}^{+}$-driven motor of E. coli (7).

\section{DISCUSSION}

Until now, two sodium-driven motor genes, mot $X$ and $\operatorname{mot} Y$, have been identified in $V$. parahaemolyticus and $V$. alginolyticus. Their products are both predicted to have one transmembrane
Flagellar motor proteins

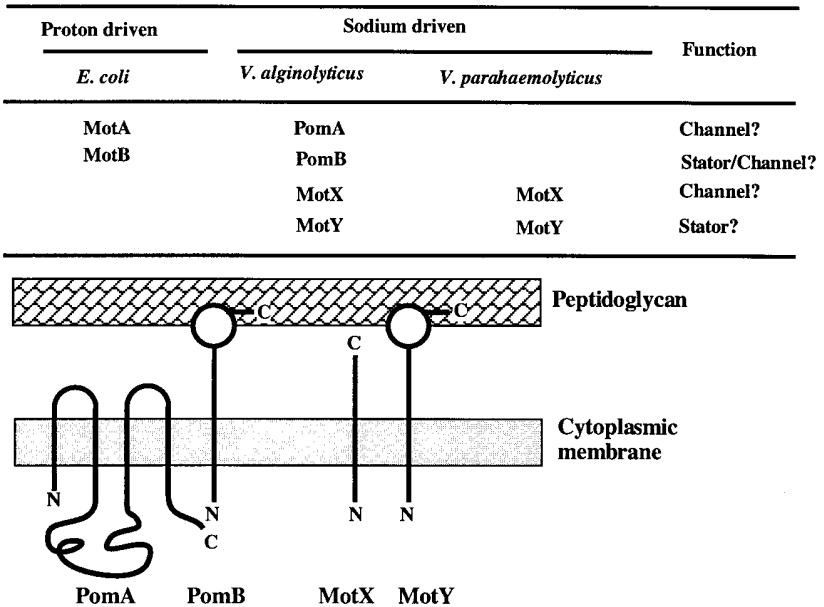

FIG. 6. Motor genes of membrane components for the proton-driven- and sodium-driven-type flagella and the predicted membrane topology of the four pom gene products.

region. It is believed that MotX is a sodium channel component and that MotY connects the motor with peptidoglycan, because its C-terminal region is significantly similar to that of OmpA in E. coli. In this study, we cloned two novel sodiumdriven motor genes, pom $A$ and pomB, which are homologous to the $m o t A$ and $m o t B$ genes of proton-driven motors, respectively. So, the sodium-driven motor consists of the products of four genes, pom $A$, pom $B, \operatorname{mot} X$, and $\operatorname{mot} Y$ (Fig. 6). The genes, lafT and laf $U$, of the lateral flagellar motor which is proton driven have been isolated, and the predicted products are shown to be homologous to the $\operatorname{mot} A$ and $\operatorname{mot} B$ products of $E$. coli, respectively (34).

By inducing the $E$. coli mot $A$ and $\operatorname{mot} B$ genes in tethered $\operatorname{mot} A$ and $\operatorname{mot} B$ mutant cells, respectively, restoration of torque took place in a series of equally spaced steps $(7,10)$. On the other hand, the rotation rate decreased stepwise in the tethered alkalophilic Bacillus cells by a photoactivated amiloride analog which covalently binds to the $\mathrm{Na}^{+}$-interaction site of a channel (36). These results suggest that the motor has multiple force-generating units and that each force-generating unit functions independently. Moreover, the torque generated by a motor is the sum of the torque generated by each unit. It has been estimated that the $\mathrm{H}^{+}$-driven motor of $E$. coli and the $\mathrm{Na}^{+}$-driven motor of alkalophilic Bacillus have 8 and 5 to 9 force-generating units, respectively. In our induction system for $\operatorname{pom} A$, the swimming speed and motile fraction of the pom $A$ mutant cells were restored to wild-type levels in $20 \mathrm{~min}$, suggesting that newly synthesized PomA proteins were successively integrated into the defective motor complexes. We have shown that the swimming ability of the mot $Y$ mutant increased with the mot $Y$ induction (40). The independent force-generating unit probably functions as described above in the $\mathrm{Na}^{+}$driven motor of $V$. alginolyticus. We plan to analyze the rotation speed at low numbers of the force-generating units by laser dark-field microscopy (38) and to investigate the stability or the stepping of the speed.

From the homology to the proton motor components and their properties $(15,39,44,45,54)$, we expect that the four transmembrane regions of PomA and the one transmembrane region of PomB also form a complex and function as a sodium channel. An Asp residue in the transmembrane region of $E$. coli MotB has been proposed to act as the donor in $\mathrm{H}^{+}$transfer 
to a recipient near the cytoplasmic side of the protein (45). The Asp is conserved in the PomB transmembrane region and may be the donor in $\mathrm{Na}^{+}$transfer to a neighboring protein. It is also possible that a sodium channel is formed from the four pom products, PomA, PomB, MotX, and MotY, because it has been suggested that MotX is the channel component of the motor and interacts with MotY (30). It is not ruled out that MotX and MotY might form a different sodium channel.

In the proton-driven motor, MotB is thought to function as a stator by interaction with peptidoglycan. PomB presumably functions in a similar way. In addition to PomB, the sodiumdriven-type motor apparently needs another component, MotY, which has a peptidoglycan binding motif but no further similarity to MotB. These two possible stators, PomB and MotY, are required for polar motility of $V$. alginolyticus.

Why does the sodium-driven motor need two stators? And why does it need four motor components, whereas the protondriven motor needs only two? Vibrio has two types of flagella, polar and lateral. The polar flagellum is thought to function as a viscosity sensor (33) that regulates expression of lateral flagellar genes. Recently, we have shown that Vibrio cells sense a decrease in the rotation rate of (or the sodium influx through) the polar flagellar motor (23). Therefore, we speculate that MotX and MotY might sense the rotation rate or the sodium flux. Alternatively, they may be needed for the very fast rotation of the sodium-driven motor. It has been reported that its speed is ca. $600 \mathrm{rps}$ in $50 \mathrm{mM} \mathrm{NaCl}$ at room temperature and increases up to ca. $1,700 \mathrm{rps}$ in $300 \mathrm{mM} \mathrm{NaCl}$ at $35^{\circ} \mathrm{C}(28$, $29,37)$, whereas the speed of the proton-driven motor is 200 to $300 \mathrm{rps}$ at most in $S$. typhimurium or E. coli $(25,26)$.

\section{ACKNOWLEDGMENTS}

We thank Linda McCarter for providing us with the strains and I. Okunishi for assistance with the pom mutant isolation. We especially thank Robert M. Macnab for critical reading of the manuscript.

This work was supported in part by grants-in-aid to I.K. and M.H. from the Ministry of Education Science and Culture of Japan and by the research and development program of NEDO of Japan.

\section{REFERENCES}

1. Atsumi, T., S. Sugiyama, E. J. Cragoe, Jr., and Y. Imae. 1990. Specific inhibition of the $\mathrm{Na}^{+}$-driven flagellar motors of alkalophilic Bacillus strains by the amiloride analog phenamil. J. Bacteriol. 172:1634-1639.

2. Atsumi, T., L. McCarter, and Y. Imae. 1992. Polar and lateral flagellar motors of marine Vibrio are driven by different ion-motive forces. Nature 355:182-184.

3. Atsumi, T., Y. Maekawa, H. Tokuda, and Y. Imae. 1992. Amiloride at pH 7.0 inhibits the $\mathrm{Na}^{+}$-driven flagellar motors of Vibrio alginolyticus but allows the cell growth. FEBS Lett. 314:114-116.

4. Atsumi, T., Y. Maekawa, T. Yamada, I. Kawagishi, Y. Imae, and M. Homma. 1996. Effect of viscosity on swimming by the lateral and polar flagella of Vibrio alginolyticus. J. Bacteriol. 178:5024-5026.

5. Bartolomé, B., Y. Jubete, E. Martinez, and F. D. Cruz. 1991. Construction and properties of a family of pACYC184-derived cloning vectors compatible with pBR322 and its derivatives. Gene 102:75-78.

6. Blair, D. F. 1995. How bacteria sense and swim. Annu. Rev. Microbiol. 49:489-522.

7. Blair, D. F., and H. C. Berg. 1988. Restoration of torque in defective flagellar motors. Science 242:1678-1681.

8. Blair, D. F., and H. C. Berg. 1990. The MotA protein of E. coli is a proton-conducting component of the flagellar motor. Cell 60:439-449.

9. Blair, D. F., and H. C. Berg. 1991. Mutations in the MotA protein of Escherichia coli reveal domains critical for proton conduction. J. Mol. Biol. 221:1433-1442.

10. Block, S. M., and H. C. Berg. 1984. Successive incorporation of forcegenerating units in the bacterial rotary motor. Nature 309:470-472.

11. Chun, S. Y., and J. S. Parkinson. 1988. Bacterial motility: membrane topology of the Escherichia coli MotB protein. Science 239:276-278.

12. De Mont, R., and J. Vanderleyden. 1994. The C-terminal sequence conservation between OmpA-related outer membrane protein and MotB suggests a common function in both Gram-positive and Gram-negative bacteria, possibly in the interaction of these domains with peptidoglycan. Mol. Microbiol. 12:333-334.
13. Francis, N. R., G. E. Sosinsky, D. Thomas, and D. J. DeRosier. 1994. Isolation, characterization and structure of bacterial flagellar motors containing the switch complex. J. Mol. Biol. 235:1261-1270.

14. Fujisaki, S., H. Hara, Y. Nishimura, K. Horiuchi, and T. Nishino. 1990. Cloning and nucleotide sequence of the isp $A$ gene responsible for farnesyl diphosphate synthase activity in Escherichia coli. J. Biochem. 108:995-1000.

15. Garza, A. G., R. Biran, J. A. Wohlschlegel, and M. D. Manson. 1996. Mutations in $m o t B$ suppressible by changes in stator or rotor components of the bacterial flagellar motor. J. Mol. Biol. 258:270-285.

16. Grant, S. N., J. Jessee, F. R. Bloom, and D. Hanahan. 1990. Differential plasmid rescue from transgenic mouse DNAs into Escherichia coli methylation-restriction mutant. Proc. Natl. Acad. Sci. USA 87:4645-4649.

17. Homma, M., H. Oota, S. Kojima, I. Kawagishi, and Y. Imae. 1996. Chemotactic responses to an attractant and a repellent in the flagellar systems of Vibrio alginolyticus. Microbiology 146:2777-2783.

18. Imae, Y. 1991. Use of $\mathrm{Na}^{+}$as an alternative to $\mathrm{H}^{+}$in energy transduction, $\mathrm{p}$. 197-221. In Y. Mukohata (ed.), New era of bioenergetics. Academic Press, Inc., Tokyo, Japan.

19. Imae, Y., and T. Atsumi. 1989. $\mathrm{Na}^{+}$-driven bacterial flagellar motors J. Bioenerg. Biomembr. 21:705-716.

20. Kaim, G., and P. Dimroth. 1995. A double mutation in subunit $\mathrm{c}$ of the $\mathrm{Na}^{+}$-specific $\mathrm{F}_{1} \mathrm{~F}_{0}$-ATPase of Propionigenium modestum results in a switch from $\mathrm{Na}^{+}$-coupled ATP synthesis in the Escherichia coli host cells. J. Mol. Biol. 253:726-738.

21. Kawagishi, I., Y. Maekawa, T. Atsumi, M. Homma, and Y. Imae. 1995 Isolation of the polar and lateral flagellum-defective mutants in Vibrio alginolyticus and identification of their flagellar driving energy sources. J. Bacteriol. 177:5158-5160.

22. Kawagishi, I., I. Okunishi, M. Homma, and Y. Imae. 1994. Removal of the periplasmic DNase before electroporation enhances efficiency of transformation in the marine bacterium Vibrio alginolyticus. Microbiology 140:23552361.

23. Kawagishi, I., M. Imagawa, Y. Imae, L. McCarter, and M. Homma. 1996. The sodium-driven polar flagellar motor of marine Vibrio as the mechanosensor that regulates lateral flagellar expression. Mol. Microbiol. 20:693699.

24. Kojima, S., T. Atsumi, K. Muramoto, S. Kudo, I. Kawagishi, and M. Homma. 1997. Vibrio alginolyticus mutants resistant to phenamil, a specific inhibitor of the sodium-driven flagellar motor. J. Mol. Biol. 265:310-318.

25. Kudo, S., Y. Magariyama, and S.-I. Aizawa. 1990. Abrupt changes in flagellar rotation observed by laser dark-field microscopy. Nature 346:677-680.

26. Lowe, G., M. Meister, and H. C. Berg. 1987. Rapid rotation of flagellar bundles in swimming bacteria. Nature 325:637-640.

27. Macnab, R. M. 1995. Flagellar switch, p. 181-199. In J. A. Hoch and T. J. Silhavy (ed.), Two-component signal transduction. ASM Press, Washington, D.C.

28. Magariyama, Y., S. Sugiyama, K. Muramoto, Y. Maekawa, I. Kawagishi, Y. Imae, and S. Kudo. 1994. Very fast flagellar rotation. Nature 371:752.

29. Magariyama, Y., S. Sugiyama, K. Muramoto, I. Kawagishi, Y. Imae, and S. Kudo. 1995. Simultaneous measurement of bacterial flagellar rotation rate and swimming speed. Biophys. J. 69:2154-2162.

30. McCarter, L. L. 1994. MotY, a component of the sodium-type flagellar motor. J. Bacteriol. 176:4219-4225.

31. McCarter, L. L. 1994. MotX, the channel component of the sodium-type flagellar motor. J. Bacteriol. 176:5988-5998.

32. McCarter, L. L. 1995. Genetic and molecular characterization of the polar flagellum of Vibrio parahaemolyticus. J. Bacteriol. 177:1595-1609.

33. McCarter, L. L., M. Hilmen, and M. Silverman. 1988. Flagellar dynamometer controls swarmer cell differentiation of Vibrio parahaemolyticus. Cell 54:345-351.

34. McCarter, L. L., and M. E. Wright. 1993. Identification of genes encoding components of swarmer cell flagellar motor and propeller and a sigma factor controlling differentiation of Vibrio parahaemolyticus. J. Bacteriol. 175:33613371.

35. Morales, V. M., A. Bäckman, and M. Bagdassarian. 1991. A series of wide host-range low-copy-number vectors that allow direct screening for recombinants. Gene 97:39-47.

36. Muramoto, K., S. Sugiyama, E. J. Cragoe, Jr., and Y. Imae. 1994. Successive inactivation of the force-generating units of sodium-driven bacterial flagellar motors by a photoreactive amiloride analog. J. Biol. Chem. 269:3374-3380.

37. Muramoto, K., I. Kawagishi, S. Kudo, Y. Magariyama, Y. Imae, and M. Homma. 1995. High speed rotation and speed stability of the sodium-driven flagellar motor in Vibrio alginolyticus. J. Mol. Biol. 251:50-58.

38. Muramoto, K., Y. Magariyama, M. Homma, I. Kawagishi, S. Sugiyama, Y. Imae, and S. Kudo. 1996. Rotational fluctuation of the sodium-driven flagellar motor of Vibrio alginolyticus induced by binding of inhibitors. J. Mol. Biol. 259:687-695.

39. Nguyen, C. C., and M. H. Saier, Jr. 1996. Structural and phylogenetic analysis of the MotA and MotB families of bacterial flagellar motor proteins. Res. Microbiol. 147:317-332.

40. Okunishi, I., I. Kawagishi, and M. Homma. 1996. Cloning and characterization of $\operatorname{mot} Y$, a gene coding for a component of the sodium-driven flagel- 
lar motor in Vibrio alginolyticus. J. Bacteriol. 178:2409-2415.

41. Sambrook, J., E. F. Fritsch, and T. Maniatis. 1989. Molecular cloning: a laboratory manual, 2nd ed. Cold Spring Harbor Laboratory, Cold Spring Harbor, N.Y.

42. Shah, D. S. H., J. P. Armitage, and R. E. Sockett. 1995. Rhodobacter sphaeroides WS8 expresses a polypeptide that is similar to MotB of Escherichia coli. J. Bacteriol. 177:2929-2932.

43. Shah, D. S. H., and R. E. Sockett. 1995. Analysis of the motA flagellar motor gene from Rhodobacter sphaeroides, a bacterium with a unidirectional, stopstart flagellum. Mol. Microbiol. 17:961-969.

44. Sharp, L. L., J. Zhou, and D. F. Blair. 1995. Features of MotA protein channel structure revealed by tryptophan-scanning mutagenesis. Proc. Natl. Acad. Sci. USA 92:7946-7950.

45. Sharp, L. L., J. Zhou, and D. F. Blair. 1995. Tryptophan-scanning mutagenesis of MotB, and integral membrane protein essential for flagellar rotation in Escherichia coli. Biochemistry 34:9166-9171.

46. Simon, R., U. Priefer, and A. Pühler. 1983. A broad host range mobilization system for in vitro genetic engineering: transposon mutagenesis in gramnegative bacteria. Bio/Technology 1:784-791.

47. Stolz, B., and H. C. Berg. 1991. Evidence for interactions between MotA and MotB, torque-generating elements of the flagellar motor of Escherichia coli.
J. Bacteriol. 173:7033-7039.

48. Sugiyama, S., E. J. Cragoe, Jr., and Y. Imae. 1988. Amiloride, a specific inhibitor for the $\mathrm{Na}^{+}$-driven flagellar motors of alkalophilic Bacillus. J. Biol. Chem. 263:8215-8219.

49. Tang, H., T. F. Braun, and D. F. Blair. 1996. Motility protein complexes in the bacterial flagellar motor. J. Mol. Biol. 261:209-221.

50. Tokuda, H., T. Nakamura, and T. Unemoto. 1981. Potassium ion is required for the generation of $\mathrm{pH}$-dependent membrane potential and $\Delta \mathrm{pH}$ by the marine bacterium Vibrio alginolyticus. Biochemistry 20:4198-4203.

51. Yamaguchi, S., S.-I. Aizawa, M. Kihara, M. Isomura, C. J. Jones, and R. M. Macnab. 1986. Genetic evidence for a switching and energy-transducing complex in the flagellar motor of Salmonella typhimurium. J. Bacteriol. 168:1172-1179.

52. Yoshida, S., S. Sugiyama, Y. Hojo, H. Tokuda, and Y. Imae. 1990. Intracellular $\mathrm{Na}^{+}$kinetically interferes with the rotation of the $\mathrm{Na}^{+}$-driven flagellar motors of Vibrio alginolyticus. J. Biol. Chem. 256:20346-20350.

53. Zhao, R., N. Pathak, H. Jaffe, T. S. Reese, and S. Khan. 1996. FliN is a major structural protein of the C-ring in the Salmonella typhimurium flagellar basa body. J. Mol. Biol. 261:195-208.

54. Zhou, J., R. T. Fazzio, and D. F. Blair. 1995. Membrane topology of the MotA protein of Escherichia coli. J. Mol. Biol. 251:237-242. 